\title{
Article
}

\section{A Study of the Minimum Thermal Power of a Nuclear Reactor}

\author{
Keith E. Holbert (D)
}

check for

updates

Citation: Holbert, K.E. A Study of the Minimum Thermal Power of a Nuclear Reactor. J. Nucl. Eng. 2021, 2, 412-421. https://doi.org/10.3390/ jne2040031

Academic Editor: Dan Gabriel Cacuci

Received: 15 September 2021

Accepted: 13 October 2021

Published: 20 October 2021

Publisher's Note: MDPI stays neutral with regard to jurisdictional claims in published maps and institutional affiliations.

Copyright: (C) 2021 by the author. Licensee MDPI, Basel, Switzerland. This article is an open access article distributed under the terms and conditions of the Creative Commons Attribution (CC BY) license (https:/ / creativecommons.org/licenses/by/ $4.0 /)$.
School of Electrical, Computer and Energy Engineering, Arizona State University, Tempe, AZ 85287, USA; holbert@asu.edu

\begin{abstract}
The minimum mass for a critical reactor is well studied whereas the minimum heat production from a nuclear reactor has received little attention. The thermal power of a (sub)critical reactor originates from fission as well as radioactive decay. Fission includes neutron-induced and spontaneous fission. For an idealized critical core, we find that the minimum theoretical power is $E_{R} / \Lambda$, whereas for a subcritical reactor comprising fissionable material undergoing spontaneous fission, the minimum power is dictated by subcritical multiplication. Interestingly, radioisotopic heat generation exceeds the minimum theoretical fission power for most of the fissile materials examined in this study.
\end{abstract}

Keywords: radioisotopic heat production; specific power; spontaneous fission; subcritical multiplication

\section{Introduction}

The original Chicago Pile 1 (CP-1) produced half a watt during its first operation and later $200 \mathrm{~W}$ [1]. It is sometimes stated casually that a nuclear reactor can operate at any power level [2-4]. That statement is typically directed at higher thermal power levels. Similarly, the rated power of a reactor is defined as an upper bound for normal operation. In contrast, the TRIGA Mark II research reactor at Mainz, Germany can reportedly be operated at a stabilized thermal power at any level from $10 \mathrm{~mW}$ to $100 \mathrm{~kW}[5,6]$, and the Reactor Critical Facility at Rensselaer Polytechnic Institute has been simulated at $0.79 \mathrm{~mW}$, and run during experiments at powers of 0.63 and $0.99 \mathrm{~mW}$ [7].

While the casual statement and the reported stable operation at milliwatts of power are motivations to determine whether there is a theoretical minimum power level, the determination of the minimum critical mass for a self-sustaining nuclear reactor is a wellstudied problem, for example, see [8,9]. The quest for determining minimum critical masses for less traditional materials is an ongoing effort. For instance, Seifritz and Wydler (1979) determined a minimum critical radius of $8.864 \mathrm{~cm}$ and mass of $59.7 \mathrm{~kg}$ for Np237 [10]. Sanchez et al. (2008) estimated a bare critical mass of $57 \pm 4 \mathrm{~kg}$ for Np-237 from a combination of experimental measurements using a neptunium sphere and Monte Carlo simulations [11]. Ronen et al. (2006) report that the smallest thermal reactor is a 4.95-kg spherical solution of ${ }^{242 \mathrm{~m}} \mathrm{Am}\left(\mathrm{NO}_{3}\right)_{2}$ in water [12].

In our pursuit for determining a lower limit for the thermal power of a reactor, we must recognize that heat can be generated from several sources within a core, specifically, fission and radioactive decay. This paper is organized with that in mind. Section 2 contemplates the theoretical power of an ideal critical reactor. Section 3 considers the more realistic situation of a reactor comprising fissionable materials that also undergo spontaneous fission. Section 4 contemplates heat production originating from conventional radioactive decay. Section 5 concludes the study.

\section{Minimum Power of an Ideal Critical Reactor}

In this section we consider an ideal critical reactor without any intrinsic sources. This analysis is performed from the perspective of an average number of neutrons rather than considering persistent chains. The formulae derived in this section are not purported to 
represent a practical minimum reactor flux or power from an operational standpoint, rather they are purely theoretical lower bounds.

\subsection{Analytical Formula}

Supposing that it is possible to establish a self-sustaining reaction in which a single fission occurs in each neutron generation, then the minimum power is

$$
P_{\min }=\frac{E_{R}}{\Lambda}
$$

where $E_{R}$ is the energy yield per fission $(\approx 200 \mathrm{MeV} /$ fission $)$ and $\Lambda$ is the generation time. The preceding equation is equivalent to saying that $v$ neutrons are present in the (finite or infinite) reactor, where $v$ is the average number of neutrons released per fission event. Figure 1 illustrates this model. For a reactor volume of $V_{R x}$ and neutron speed of $v$, the corresponding neutron density and flux are $n=v / V_{R x}$ and $\phi_{\min }=n v=v v / V_{R x}$, respectively. Thus, the same minimum power is obtained from the definition of reactor power based on the neutron flux

$$
P_{\min }=E_{R} \Sigma_{\mathrm{f}} \phi_{\min } V_{R x}=E_{R} \Sigma_{\mathrm{f}}(v v)=\frac{E_{R}}{\Lambda}
$$

where the definition of generation time, $\Lambda=1 /\left(v \vee \Sigma_{\mathrm{f}}\right)[13,14]$, is employed. The generation time is the period between the birth of a neutron and the production of new neutrons by fission, whereas the neutron lifetime is the time between neutron emission and absorption [15]. Because the generation time and prompt neutron lifetime $\ell_{p}$ for a finite reactor are equal for a critical reactor, or more precisely $\Lambda=\ell_{p} / k_{\text {eff }}$ [16], the formula may also be written as $P_{\min }=E_{R} / \ell_{p}$. Appendix A provides a more detailed derivation of this minimum power beginning with the point kinetics equations. While the neutron lifetime in an infinite reactor is $\ell_{\infty}=1 /\left(v \Sigma_{\mathrm{a}}\right)$, leakage from a finite assembly reduces the lifetime by the nonleakage probability $\mathcal{L}$ (i.e., $\ell_{p}=\mathcal{L} \ell_{\infty}$ ). With the average neutron lifetime in a reflected reactor being larger than that of a bare reactor [17], the minimum power of a reflected reactor would be less than a bare reactor using the same fissionable material.

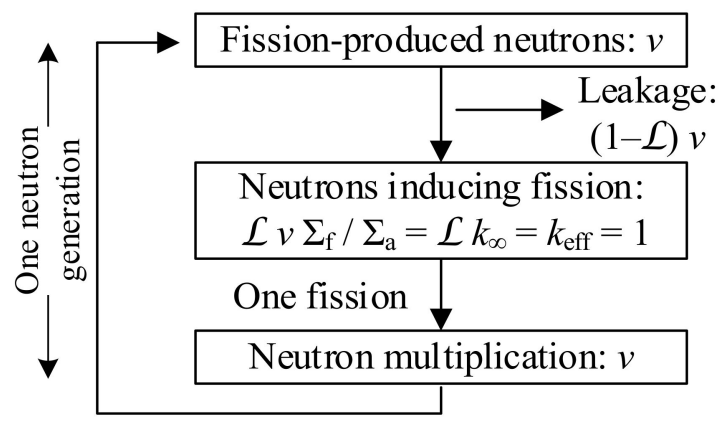

Figure 1. Lifecycle of neutrons in a single fission per generation reactor. The nonleakage probability is $\mathcal{L}$; the infinite and effective multiplication factors are $k_{\infty}$ and $k_{\text {eff }}$; the fission and absorption macroscopic cross-sections are $\Sigma_{\mathrm{f}}$ and $\Sigma_{\mathrm{a}}$.

\subsection{Numerical Results}

As an order-of-magnitude estimate of the minimum power, consider an actual fast reactor, specifically the historic Lady Godiva I assembly [18] of Los Alamos National Laboratory (LANL). Using fast group constants such as $v=2.60$ which ultimately originate from the early 1960s [19], Bowen and Busch calculated a macroscopic fission cross-section $\Sigma_{\mathrm{f}}$ of $0.06314 \mathrm{~cm}^{-1}$ for a one-speed representation of the bare, $93.5 \%$ enriched Godiva [20]. The average neutron energy using the Watt [21] U-235 fission spectrum can be calculated as $2 \mathrm{MeV}$ [22]. Assuming 2-MeV neutrons gives a minimum fission power of 


$$
P_{\min }=E_{R} \Sigma_{\mathrm{f}} v v=\left(\frac{200 \mathrm{MeV}}{\text { fission }}\right)\left(\frac{0.06314}{\mathrm{~cm}}\right)(2.60 \mathrm{n})\left(\frac{1.96 \times 10^{9} \mathrm{~cm}}{\mathrm{~s}}\right)\left(\frac{1.602 \times 10^{-13} \mathrm{~J}}{\mathrm{MeV}}\right)=10 \mathrm{~mW}
$$

The $E_{R}$ utilized is not exact but varies around $200 \mathrm{MeV} /$ fission for nuclides as can be seen in the tabulations by Sher [23]. For comparison, Godiva reactivity measurements were typically carried out at power levels from 0.1 to $1 \mathrm{~W}$ [24]. Similarly, the fission crosssection for LANL's unreflected Jezebel assembly [25] was calculated as $0.07274 \mathrm{~cm}^{-1}$ [20] for delta-phase Pu-239 which leads to a $P_{\min }$ of $14 \mathrm{~mW}$ using $v=2.98$. Thermal power in the milliwatt regime certainly implies a zero-power reactor for which reactivity feedback effects are ignored. In order to expand the list of nuclides and as a rudimentary sensitivity analysis, modern JENDL (Japanese Evaluated Nuclear Data Library) 4.0 fission-spectrumaveraged cross-sections [26] were utilized in this study, and the results are compared in Table 1 . The fast reactor physics parameters lead to minimum powers in the low $\mathrm{mW}$.

Table 1. Minimum power for an idealized spherical critical fast reactor.

\begin{tabular}{ccc}
\hline Nuclide & $\begin{array}{c}\boldsymbol{P}_{\min }(\mathbf{m W}) \text { from Circa 1960s } \\
\text { Neutron Physics Data }\end{array}$ & $\begin{array}{c}\boldsymbol{P}_{\min }(\mathbf{m W}) \text { from JENDL 4.0 } \\
\text { Neutron Physics Data }\end{array}$ \\
\hline $\mathrm{U}-233$ & $\mathrm{n} / \mathrm{a}$ & 14 \\
$\mathrm{U}-235$ & 11 & 9 \\
$\mathrm{~Np}-237$ & $\mathrm{n} / \mathrm{a}$ & 11 \\
$\mathrm{Pu}-239(\alpha)$ & 17 & 16 \\
$\mathrm{Pu}-239(\delta)$ & 14 & 13 \\
$\mathrm{Am}-242 \mathrm{~m}$ & $\mathrm{n} / \mathrm{a}$ & 11 \\
\hline
\end{tabular}

${ }^{1}$ Reference [19] provided fast cross-section data for U-235, U-238, and Pu-239 only.

Recognizing that thermal neutron microscopic cross-sections for fissile materials are about two orders of magnitude larger than their fast counterparts but the thermal neutron speed is about four orders of magnitude smaller, we surmise that the minimum thermal power for a thermal reactor would be at least two orders of magnitude smaller, especially given that fuel atomic densities will likely be much smaller than those of Godiva and Jezebel. Moreover, for a thermal reactor the neutron lifetime depends more so on the neutron diffusion time within the moderator. For instance, light water has a thermal diffusion time of about $2.1 \times 10^{-4} \mathrm{~s}$ [15], which yields a minimum power of

$$
P_{\min }=\frac{E_{R}}{\ell_{p}}=\frac{(200 \mathrm{MeV})\left(1.602 \times 10^{-13} \mathrm{~J} / \mathrm{MeV}\right)}{\left(2.1 \times 10^{-4} \mathrm{~s}\right)}=1.5 \times 10^{-7} \mathrm{~W}
$$

Similarly, Table 2 lists the minimum power based on four different moderators, although we recognize that the overall diffusion time depends on the fuel and configuration. For instance, in a homogeneous fuel-moderator mixture, the diffusion time would be reduced by a multiplier of $1-f$ where $f(\leq 1)$ is the thermal utilization. In the case of the graphite-moderated Peach Bottom High-Temperature Gas-Cooled Reactor (HTGR), Preskitt et al. (1967) measured the generation time as approximately $0.2 \mathrm{~ms}$, varying based on the control rod configuration [27]; using Equation (4), the corresponding $P_{\min }$ is $160 \mathrm{nW}$.

Table 2. Minimum power based solely on the moderator for a thermal reactor.

\begin{tabular}{ccc}
\hline Moderator & Diffusion Time (s) ${ }^{\mathbf{1}}$ & Minimum Power (nW) $^{(\mathbf{n}}$ \\
\hline Light water & 0.00021 & 150 \\
Heavy water & 0.043 & 0.75 \\
Beryllium & 0.0039 & 8.2 \\
Graphite & 0.017 & 1.9 \\
\hline
\end{tabular}

${ }^{1}$ Neutron diffusion times are from [15]. 
The results of this section, however, are too idealistic as fissionable materials undergo spontaneous fission resulting in the presence of far greater numbers of neutrons than $v$ in each generation. In addition, heat can be generated from pre-existing fission fragments and activation products in a critical core. The author recognizes that maintaining such a low power is impractical, especially in the absence of a dedicated neutron source. It is well-known that a neutron source is necessary for instrumentation purposes to ensure statistical significance in the measurement of flux [28] especially at start-up conditions. This latter item is an impetus to examine whether a similar limit exists for subcritical reactors. Nonetheless, we have established a reference point for $P_{\min }$.

\section{Minimum Power of Subcritical Reactor with Intrinsic Source(s)}

The presence of inherent neutron sources within fissionable material leads to a steadystate background flux and the concomitant subcritical multiplication. In fact, Ruby argues that "all [reactor] steady states are subcritical" due to the presence of an endogenous source and small reactivity oscillations [29]. Intrinsic sources within a reactor include neutron emission from spontaneous fission and $(\gamma, \mathrm{n})$ and $(\alpha, \mathrm{n})$ reactions. This section focuses on the former, but $(\alpha, n)$ reactions would readily occur in oxide fuels.

\subsection{Analytical Formula}

For a subcritical reactor of reactivity $\rho$, the neutron density due to a volumetric source term, $S \mathrm{n} /\left(\mathrm{cm}^{3} \cdot \mathrm{s}\right)$, is known to be $[4,30]$

$$
n=\frac{-\Lambda S}{\rho}
$$

This relation, which accounts for subcritical multiplication, is used to determine the corresponding fission power

$$
P=E_{R} \Sigma_{\mathrm{f}}(n v) V_{R x}=\frac{E_{R} S V_{R x}}{-\rho v}
$$

Escalona also provides the preceding expression [31].

The subcritical multiplication factor $M=1 /\left(1-k_{\text {eff }}\right)$ can be used to distinguish the contribution from the original intrinsic source neutrons from that due to the multiplication [32]. The corresponding decomposition of the power results in

$$
P=P_{\text {intrinsic }}+P_{\text {fission }}=\frac{E_{R} S V_{R x} k_{\text {eff }}}{v}+\frac{E_{R} S V_{R x} k_{\text {eff }}}{-\rho v}
$$

The fraction of the power production from the original source neutrons is $1-k_{\text {eff }}$.

\subsection{Spontaneous Fission Neutron Yields}

Using the branching fraction $F$ and average number of neutrons emitted for spontaneous fission $v_{s p}$, the neutron yield may be determined from

$$
Y=F v_{s p} \frac{\lambda N_{\mathrm{A}}}{M}
$$

where $N_{\mathrm{A}}$ is the Avogadro constant, and $\lambda$ is the overall effective decay constant of the radioisotope and $M$ is its atomic mass. Table 3 lists some pertinent total half-lives and spontaneous fission branching factors as obtained from [33-35] and $v_{s p}$ values from [36] along with the calculated neutron yield. 
Table 3. Spontaneous fission characteristics.

\begin{tabular}{ccccc}
\hline Nuclide & $\begin{array}{c}\text { Total } \\
\text { Half-Life (y) }\end{array}$ & $\begin{array}{c}\text { Branching } \\
\text { Factor (\%) }\end{array}$ & $\begin{array}{c}\text { Neutrons } \\
\text { Released per Fission, } \boldsymbol{~}_{\boldsymbol{s} \boldsymbol{p}}\end{array}$ & $\begin{array}{c}\text { Neutron Yield } \\
\mathbf{( n / ( g \cdot s )})\end{array}$ \\
\hline U-233 & $1.59 \times 10^{5}$ & $<6 \times 10^{-11}$ & 1.76 & $3.76 \times 10^{-4}$ \\
$\mathrm{U}-235$ & $7.04 \times 10^{8}$ & $7 \times 10^{-9}$ & 1.86 & $1.04 \times 10^{-5}$ \\
U-238 & $4.46 \times 10^{9}$ & $5 \times 10^{-5}$ & 2.01 & $1.25 \times 10^{-2}$ \\
Np-237 & $2.14 \times 10^{6}$ & $2.1 \times 10^{-10}$ & 2.05 & $1.12 \times 10^{-4}$ \\
Pu-239 & $2.411 \times 10^{4}$ & $3 \times 10^{-10}$ & 2.16 & $1.49 \times 10^{-2}$ \\
Am-242m & 141 & $<4.7 \times 10^{-9}$ & 2.34 & $4.26 \times 10^{1}$ \\
Cf-252 & 2.65 & 3.1 & 3.765 & $2.32 \times 10^{12}$ \\
\hline
\end{tabular}

While seeking up-to-date spontaneous fission data, it was found that many of the $v_{s p}$ values ultimately rely upon measured and estimated data that are now more than 50 years old. Manero and Konshin provided a comprehensive list of twenty-one measured prompt $v_{s p}$ values in 1972 [37]. A decade later, Perry and Wilson expanded upon this list by estimating $v_{s p}$ for twenty other actinides including U-233, U-235, Np-237, Pu-239, and Am-242m, and they augmented all of the 1972 prompt data by adding an assumed delayed $v_{s p}$ value of 0.01 based on a measurement for just Cf-252 [36]. The majority of Ensslin's (1991 and 1998) data [38,39] would then hail from Perry and Wilson (1981). Interestingly, both Shores (2001) [40] and more recently Verbeke et al. (2014) [41] (with a couple of typographic errors) utilize the Perry and Wilson values except for the Pu-241 $v_{s p}$ which is taken from Ensslin because of its absence from Perry and Wilson. Shores employed these data for the SOURCES computer code [42]. Of note, Santi and Miller (2008) provided an extensive list of consensus values for $v_{s p}$ including values of $1.98 \pm 0.03$ for U-238 and $3.757 \pm 0.010$ for Cf-252 [43].

More important than the differences in $v_{s p}$ are the refinements in the spontaneous fission half-lives. Improvements in the half-life data have resulted in significant changes in the calculated neutron yield. For instance, the spontaneous fission yields given in the well-known Passive Nondestructive Assay of Nuclear Materials (1991) [38] for U-233 and $\mathrm{Pu}-239$ are 0.00086 and $0.0218 \mathrm{n} /(\mathrm{s} \cdot \mathrm{g})$, respectively, which are $130 \%$ and $47 \%$ different from those computed in this investigation with up-to-date spontaneous fission half-lives.

\subsection{Numerical Results}

Using Equation (6), calculations of the fission power at subcriticality are performed for three fissionable isotopes: U-235, U-238, and Pu-239. For each nuclide, the bare mass required to achieve a given subcritical reactivity was first computed using the JENDL 4.0 fast group constants [26]. Figure 2 shows the thermal power for $k_{\text {eff }} \leq 0.9999999$ for U-235 and $\mathrm{Pu}-239$, and $k_{\text {eff }} \leq 0.99$ for U-238. Although Pu-239 has a higher spontaneous fission yield than U-238, because of its greater subcritical mass U-238 exhibits a larger power than $\mathrm{Pu}-239$. For comparison, the minimum power for a critical mass of pure U-235 and Pu-239 using circa 1960s reactor physics constants substituted into Equation (2) is 11 and $14 \mathrm{~mW}$, respectively, as given in Table 1. 


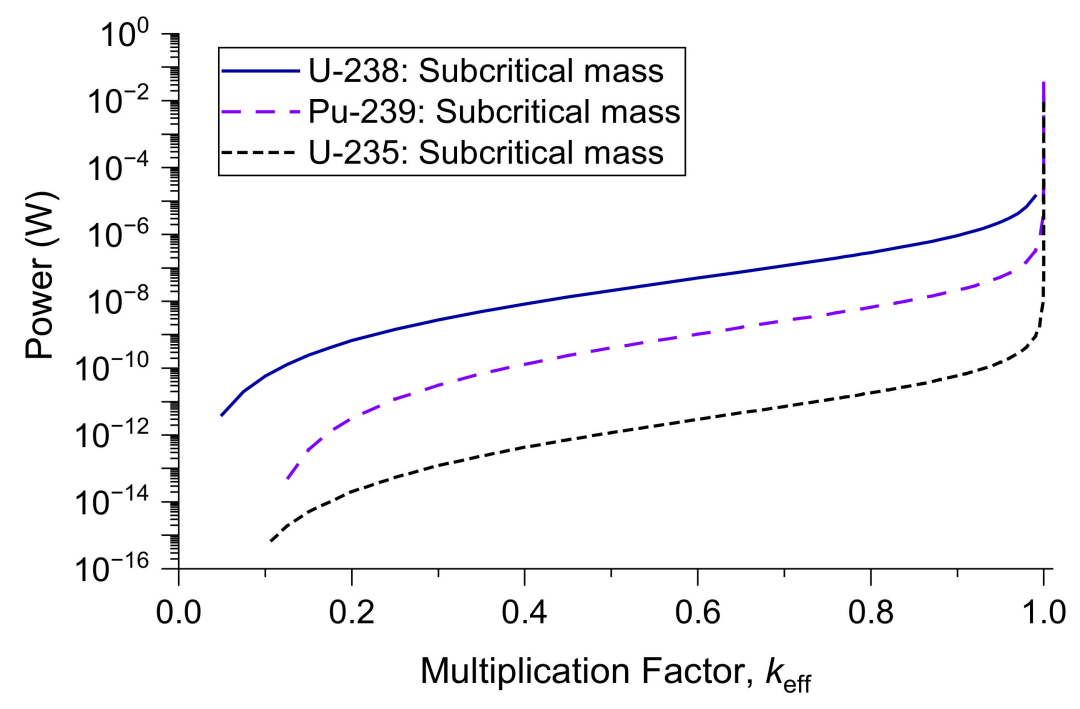

Figure 2. Reactor power from spontaneous fission and subcritical multiplication within bare spherical metal assemblies of subcritical mass comprised solely of the indicated fissionable isotope.

Because both the U-235 and Pu-239 masses can achieve criticality, we may obtain an alternative expanded view of the results. In particular, we can calculate the power for both (i) a subcritical mass and (ii) a critical mass at subcriticality. Figure 3 shows these results. Once $\rho>-0.01$, the curves for the two cases are indistinguishable.

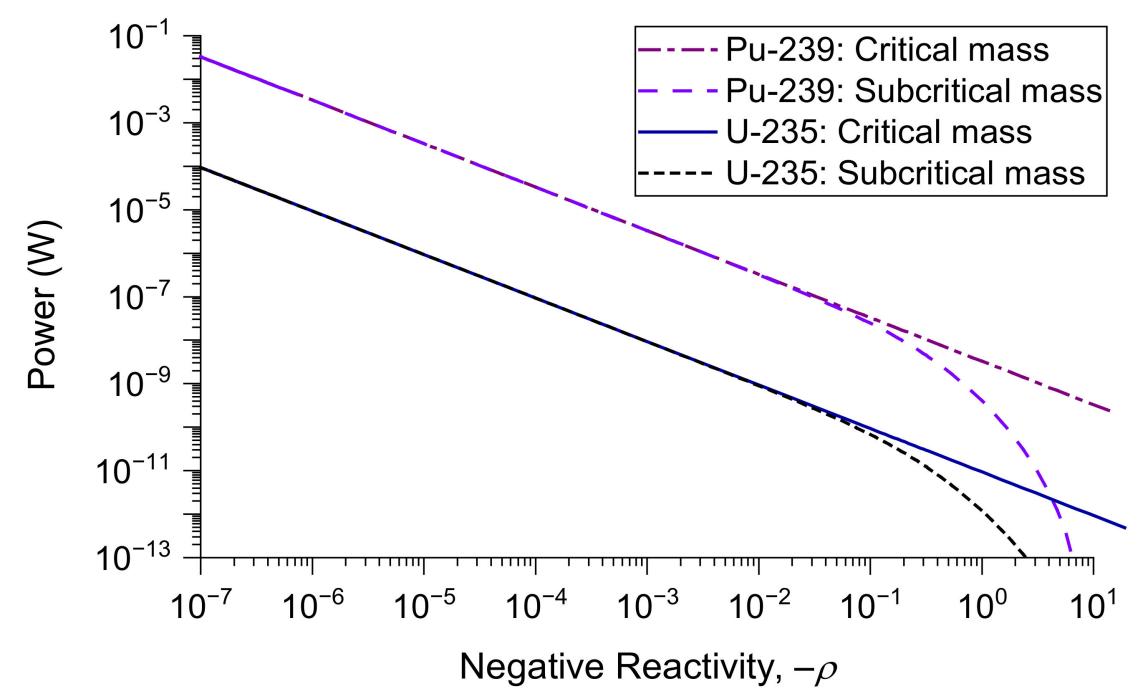

Figure 3. Total reactor power from spontaneous fission and subcritical multiplication within bare spherical metal assemblies consisting of a subcritical mass or a critical mass at subcriticality.

For the same fissionable material, a reflected reactor with its reduced mass and larger neutron lifetime exhibits a smaller minimum power than a bare assembly. The impact of the decreased mass is seen in the diminished spontaneous fission source $\left(S V_{R x}\right)$ within Equation (6). From the neutron lifetime perspective, the decreased minimum power of the reflected reactor can be obtained using Equation (4). To gauge the difference, consider LANL's Topsy [44] which was the reflected version of Godiva. Godiva with a critical mass of $48.8 \mathrm{~kg}$ was approximately three times larger than the $16.28 \mathrm{~kg}$ natural uranium reflected Topsy [19]. The Rossi-alpha at delayed critical $\left(\alpha_{d c}=-\beta / \ell_{p}\right)$ for Godiva and Topsy were -110 and -37 , respectively, $\times 10^{4} / \mathrm{s}$, and the delayed neutron fractions $(\beta)$ were 0.0066 and 0.0072 [19]. This leads to minimum powers of 5.3 and $1.7 \mathrm{~mW}$ for the bare Godiva and 
reflected Topsy, respectively. For Jezebel with a delayed critical Rossi- $\alpha$ of $-65 \times 10^{4} / \mathrm{s}$ and $\beta$ of 0.0019 [19], the corresponding minimum power is

$$
P_{\min }=\frac{E_{R}}{\ell_{p}}=\frac{-\alpha_{d c} E_{R}}{\beta}=\frac{\left(65 \times 10^{4} / \mathrm{s}\right)(200 \mathrm{MeV})\left(1.602 \times 10^{-13} \mathrm{~J} / \mathrm{MeV}\right)}{(0.0019)}=0.011 \mathrm{~W}
$$

For Popsy—the reflected version of Jezebel一the $\alpha_{d c}$ was $-20 \times 10^{4} / \mathrm{s}[25,45]$, indicating a minimum power of less than one-third of Jezebel. The $P_{\min }$ values obtained using the Rossi- $\alpha$ differ from those using the cross-sections due to simplifications such as the assumed average neutron energy of $2 \mathrm{MeV}$ and the purity of the materials in the latter approach (e.g., the $P_{\min }=14 \mathrm{~mW}$ value for Jezebel in Section 2.2 is based on cross-sections for pure Pu-239 whereas Jezebel was actually composed of about 4.5\% Pu-240 [25]).

\section{Radioisotopic Heat Production}

The earlier analyses in this paper have focused on thermal power generation from fission; however, an additional heat source exists due to radioactive decay besides spontaneous fission. The specific power from radioactive decay can be computed from the reaction $Q$ value of radionuclides exclusively undergoing alpha decay. The $Q$ value is determined from the parent $P$ and daughter $D$ atomic masses $M$ and speed of light $c$ using

$$
Q=\left[M_{P}-\left(M_{\mathrm{He}-4}+M_{D}\right)\right] c^{2}
$$

Subsequently, the specific power is obtained from the half-life $t_{H}$ of the parent via

$$
S P=Q \frac{\ln (2) N_{\mathrm{A}}}{t_{H} M_{P}}
$$

Using $Q$ for beta decay is inappropriate because the neutrino energy will most likely be deposited at a great distance. Common alpha emitters include U-233, U-235, U-238, $\mathrm{Pu}-239$, and Np-237, whereas Pu-241 decays by beta emission.

Using the above relations along with half-lives from NuDat 2.8 [46] and atomic masses from [47], the specific powers of U-235 and Pu-239 are found to be $59.9 \mathrm{nW} / \mathrm{g}$ and $1.93 \mathrm{~mW} / \mathrm{g}$, respectively. In comparison, the theoretical minimum fission power for the minimum mass (ideal) critical reactors of U-235 and Pu-239(ס) are $170 \mathrm{nW} / \mathrm{g}$ and $1.26 \mu \mathrm{W} / \mathrm{g}$, respectively, using the JENDL 4.0 data. Table 4 contrasts these values for multiple fissile nuclides, with most found to have a larger radioisotopic specific power than minimum fission power. The exception is the U-235 reactor, for which the minimum fission power is about three times larger than the radioisotopic heat generation. In the case of $\mathrm{Pu}-239$, the heat production from radioactive decay is about three orders of magnitude larger than that of the minimum fission power. With respect to the plutonium, Stout and Jones state that a mass of Pu-239 is warm to the touch [48].

Table 4. Comparison of minimum fission power and radioisotopic specific power.

\begin{tabular}{ccc}
\hline Nuclide & $\boldsymbol{P}_{\min }(\mu \mathrm{W} / \mathbf{g})^{\mathbf{1}}$ & $\boldsymbol{S P}(\boldsymbol{\mu W} / \mathbf{g})$ \\
\hline $\mathrm{U}-233$ & 0.724 & 280 \\
$\mathrm{U}-235$ & 0.17 & 0.0599 \\
$\mathrm{~Np}-237$ & 0.337 & 20.7 \\
$\mathrm{Pu}-239(\alpha)$ & 0.648 & 1930 \\
$\mathrm{Pu}-239(\delta)$ & 1.26 & 1930 \\
$\mathrm{Am}-242 \mathrm{~m}$ & 0.51 & 4600 \\
\hline
\end{tabular}

${ }^{1}$ Using the JENDL 4.0 fission-spectrum-averaged cross-section data.

\section{Summary}

For an idealized critical reactor without intrinsic neutron and heat sources, we have found minimum power levels on the order of milliwatts and nanowatts for fast and thermal 
reactors, respectively. Somewhat surprising is that heat generation from conventional radioactive decay substantially exceeds the theoretical minimum fission power for most of the studied fissile materials.

Funding: This research received no external funding.

Institutional Review Board Statement: Not applicable.

Informed Consent Statement: Not applicable.

Data Availability Statement: The data presented in this study are available in this article.

Conflicts of Interest: The author declares no conflict of interest.

\section{Appendix A}

Using the point kinetics equations, this appendix provides a derivation of the minimum power for the ideal critical reactor presented in Section 2. The generation-time formulation of the point kinetics equations for the reactor power can be written as [30]

$$
\frac{d P}{d t}=\frac{\rho-\beta}{\Lambda} P+v E_{R} \Sigma_{\mathrm{f}} V_{R x} \lambda C
$$

in which $\beta$ is the delayed neutron fraction, $C$ is the delayed neutron precursor concentration, and $\lambda$ is its decay constant. For steady-state, critical conditions, the power is algebraically determined as

$$
P=\frac{E_{R}}{v \beta / \lambda}\left(C V_{R x}\right)
$$

The ratio $\beta / \lambda$ is recognized as the average (or effective) neutron lifetime.

The precursor equation can be written as

$$
\frac{d C}{d t}=\frac{\beta}{\Lambda} n-\lambda C
$$

In similar fashion, at steady-state conditions, the precursor concentration is

$$
C=\frac{\beta}{\lambda \Lambda} n
$$

Substituting Equation (A4) into (A2) gives

$$
P=\frac{E_{R}}{v \beta / \lambda}\left(\frac{\beta}{\lambda \Lambda} n V_{R x}\right)=\frac{E_{R}}{v} \frac{n V_{R x}}{\Lambda}
$$

If, as premised in Section 2, the number of neutrons released within the core is $v$, then the same final expression as Equation (1) results

$$
P_{\min }=\frac{E_{R}}{v} \frac{n V_{R x}}{\Lambda}=\frac{E_{R}}{\Lambda}
$$

This formula makes physical sense as the minimum power being produced by a single fission event for each neutron generation.

\section{References}

1. Fermi, E. Experimental Production of a Divergent Chain Reaction. Am. J. Phys. 1952, 20, 536-558. [CrossRef]

2. Liverhant, S.E. Elementary Introduction to Nuclear Reactor Physics; Wiley: New York, NY, USA, 1960; p. 291.

3. Yadigaroglu, G. Nuclear Reactors: Physics and Materials. Chimia 2005, 59, 877-886. [CrossRef]

4. Lewis, E.E. Fundamentals of Nuclear Reactor Physics; Academic Press: London, UK, 2008; pp. 126, 221.

5. Geppert, C.; Eberhardt, K.; Karpuk, S. Status and scientific use of the TRIGA research reactor at the University of Mainz. In Proceedings of the European Research Reactor Conference, European Nuclear Society, Berlin, Germany, 13-17 March 2016; pp. 208-214. 
6. Riemer, J.; Eberhardt, K.; Geppert, C.; Gorges, C.; Karpuk, S. Status and scientific use of the TRIGA research reactor at the University of Mainz. Int. J. Nucl. Power 2019, 64, 463-468.

7. Dumonteil, E.; Bahran, R.; Cutler, T.; Dechenaux, B.; Grove, T.; Hutchinson, J.; McKenzie, G.; McSpaden, A.; Monange, W.; Nelson, M.; et al. Patchy nuclear chain reactions. Commun. Phys. 2021, 4, 1-10. [CrossRef]

8. Goertzel, G. Minimum critical mass and flat flux. J. Nucl. Energy (1954) 1956, 2, 193-201. [CrossRef]

9. Wilkins, J.E., Jr.; Srivastava, K.N. Minimum critical mass nuclear reactors. Part I. Nucl. Sci. Eng. 1982, 82, 307-315. [CrossRef]

10. Seifritz, W.; Wydler, P. Criticality of Neptunium-237 and Its Possible Utilization in Nuclear Reactors. Nucl. Sci. Eng. 1979, 72, 272-276. [CrossRef]

11. Sanchez, R.; Loaiza, D.; Kimpland, R.; Hayes, D.; Cappiello, C.; Chadwick, M. Criticality of a ${ }^{237}$ Np sphere. Nucl. Sci. Eng. 2008, 158, 1-14. [CrossRef]

12. Ronen, Y.; Fridman, E.; Shwageraus, E. The Smallest Thermal Nuclear Reactor. Nucl. Sci. Eng. 2006, 153, 90-92. [CrossRef]

13. Weaver, L.E. Reactor Dynamics and Control; Elsevier: New York, NY, USA, 1968; p. 39.

14. Lewins, J. Nuclear Reactor Kinetics and Control; Pergamon: Oxford, UK, 1978; p. 57.

15. Lamarsh, J.R.; Baratta, A.J. Introduction to Nuclear Engineering, 3rd ed.; Prentice Hall: Upper Saddle River, NJ, USA, 2001; pp. 330-333.

16. Ott, K.O.; Neuhold, R.J. Introductory Nuclear Reactor Dynamics; American Nuclear Society: La Grange Park, IL, USA, 1985; pp. 23-26.

17. Lamarsh, J.R. Introduction to Nuclear Reactor Theory; Addison-Wesley: Reading, MA, USA, 1966; pp. $435-436$.

18. Paxton, H.C. Critical assemblies at Los Alamos. Nucleonics 1955, 13, 48-50.

19. Argonne National Laboratory. Reactor Physics Constants, 2nd ed.; ANL-5800; U.S. Atomic Energy Commission: Washington, DC, USA, 1963; pp. 581-585, 617-619.

20. Brown, D.G.; Busch, R.D. Hand Calculation Methods for Criticality Safety-A Primer; LA-14244-M; Los Alamos National Laboratory: Los Alamos, NM, USA, 2006; pp. 31-36.

21. Watt, B.E. Energy Spectrum of Neutrons from Thermal Fission of U235. Phys. Rev. 1952, 87, 1037-1041. [CrossRef]

22. Kodeli, I.; Trkov, A.; Capote, R.; Nagaya, Y.; Maslov, V. Evaluation and use of the prompt fission neutron spectrum and spectra covariance matrices in criticality and shielding. Nucl. Instrum. Methods Phys. Res. Sect. A 2009, 610, 540-552. [CrossRef]

23. Sher, R. Fission energy release for 16 fissioning nuclides. In Proceedings of the Conference on Nuclear Data Evaluation Methods and Procedures, Brookhaven National Laboratory, BNL-NCS-51363, Upton, NY, USA, 22-25 September 1980; Volume 2, pp. 835-860.

24. Peterson, R.E.; Newby, G.A. An Unreflected U-235 Critical Assembly. Nucl. Sci. Eng. 1956, 1, 112-125. [CrossRef]

25. Jarvis, G.A.; Linenberger, G.A.; Orndoff, J.D.; Paxton, H.C. Two Plutonium-Metal Critical Assemblies. Nucl. Sci. Eng. 1960, 8 , 525-531. [CrossRef]

26. Shibata, K.; Iwamoto, O.; Nakagawa, T.; Iwamoto, N.; Ichihara, A.; Kunieda, S.; Chiba, S.; Furutaka, K.; Otuka, N.; Ohsawa, T.; et al. JENDL-4.0: A new library for nuclear science and engineering. J. Nucl. Sci. Technol. 2011, 48, 1-30. Available online: https: / / wwwndc.jaea.go.jp/jendl/j40/j40.html (accessed on 13 August 2021).

27. Preskitt, C.A.; Nephew, E.A.; Brown, J.R.; Van Howe, K.R. Interpretation of Pulsed-Source Experiments in the Peach Bottom HTGR. Nucl. Sci. Eng. 1967, 29, 283-295. [CrossRef]

28. Harrer, J.M.; Beckerley, J.G. Nuclear Power Reactor Instrumentation Systems Handbook, Volume 1; U.S. Atomic Energy Commission: Springfield, VA, USA, 1973; pp. 24-25.

29. Ruby, L. A problem in the teaching of reactor kinetics. Nucl. Sci. Eng. 1991, 107, 394-396. [CrossRef]

30. Kerlin, T.W.; Upadhyaya, B.R. Dynamics and Control of Nuclear Reactors; Academic Press: London, UK, 2019; pp. $23-24,53$.

31. Escalona, J. Evaluation de la Puissance d'un Reacteur en Regime Sous-Critique (Power Assessment of a Reactor in Subcritical Regime). C.E.A. Report No. 305. 1960, pp. 13, 24. Available online: https://inis.iaea.org/search/search.aspx?orig_q=RN:46012581 (accessed on 3 March 2020).

32. Murray, R.L. Nuclear Reactor Physics; Prentice-Hall: Englewood Cliffs, NJ, USA, 1957; pp. 164-167.

33. Holden, N.E.; Hoffman, D.C. Spontaneous fission half-lives for ground-state nuclides. Pure Appl. Chem. 2000, 72, 1525-1562. [CrossRef]

34. Holden, N.E.; Hoffman, D.C. Errata: Spontaneous fission half-lives for ground-state nuclides. Pure Appl. Chem. 2001, 73, 1225-1227. [CrossRef]

35. Holden, N.E. Table of the isotopes. In CRC Handbook of Chemistry and Physics, 102nd ed.; Rumble, J.R., Ed.; CRC Press/Taylor \& Francis: Boca Raton, FL, USA, 2021.

36. Perry, R.T.; Wilson, W.B. Neutron Production from $(\alpha, n)$ Reactions and Spontaneous Fission in $\mathrm{ThO}_{2}, \mathrm{UO}_{2}$, and $(\mathrm{U}, \mathrm{Pu}) \mathrm{O}_{2} \mathrm{Fuels}$; LA-8869-MS; Los Alamos National Laboratory: Los Alamos, NM, USA, 1981.

37. Manero, F.; Konshin, V.A. Status of the energy-dependent $v$-values for the heavy isotopes $(\mathrm{Z}>90)$ from thermal to $15 \mathrm{MeV}$ and of v-values for spontaneous fission. At. Energy Rev. 1972, 10, 637-756. Available online: https:/ /www-nds.iaea.org/publications/ indc/indc-nds-0034/ (accessed on 14 August 2021).

38. Ensslin, N. The origin of neutron radiation. In Passive Nondestructive Assay of Nuclear Materials; Reilly, D., Ensslin, N., Smith, H., Jr., Eds.; NUREG/CR-5550, LA-UR-90-732; Los Alamos National Laboratory: Los Alamos, NM, USA, 1991; pp. 337-356.

39. Ensslin, N.; Harker, W.C.; Krick, M.S.; Langner, D.G.; Pickrell, M.M.; Stewart, J.E. Application Guide to Neutron Multiplicity Counting; LA-13422-M; Los Alamos National Laboratory: Los Alamos, NM, USA, 1998; p. 43. 
40. Shores, E.F. Data updates for the SOURCES-4A computer code. Nucl. Instrum. Methods Phys. Res. B 2001, 179, 78-82. [CrossRef]

41. Verbeke, J.; Hagmann, C.; Wright, D. Simulation of Neutron and Gamma Ray Emission from Fission and Photofission; UCRL-AR-228518; Lawrence Livermore National Laboratory: Livermore, CA, USA, 2014.

42. Wilson, W.; Perry, R.; Charlton, W.; Parish, T. Sources: A code for calculating (alpha, n), spontaneous fission, and delayed neutron sources and spectra. Prog. Nucl. Energy 2009, 51, 608-613. [CrossRef]

43. Santi, P.; Miller, M. Reevaluation of Prompt Neutron Emission Multiplicity Distributions for Spontaneous Fission. Nucl. Sci. Eng. 2008, 160, 190-199. [CrossRef]

44. White, R.H. Topsy, A Remotely Controlled Critical Assembly Machine. Nucl. Sci. Eng. 1956, 1, 53-61. [CrossRef]

45. Koch, L.J.; Paxton, H.C. Fast reactors. Annu. Rev. Nucl. Sci. 1959, 9, 437-472. [CrossRef]

46. National Nuclear Data Center. NuDat 2.8 Database. Brookhaven National Laboratory. Available online: www.nndc.bnl.gov/ nudat2/ (accessed on 12 August 2021).

47. Wang, M.; Audi, G.; Wapstra, A.H.; Kondev, F.G.; MacCormick, M.; Xu, X.; Pfeiffer, B. The AME2012 atomic mass evaluation (II): Tables, graphs and references. Chin. Phys. C 2012, 36, 1603-2014. [CrossRef]

48. Stout, J.W.; Jones, W.M. A Calorimetric Determination of the Energy Produced by Plutonium (239). Phys. Rev. 1947, 71, 582-585. [CrossRef] 